DOCUMENTO DE REFLEXIÓN. NO DERIVADO DE INVESTIGACIÓN
Recibido: 23/10/2013

Revisado: 23/11/2013

Aprobado: 23/12/2013

\title{
LA CONSTRUCCIÓN DE AMÉRICA A TRAVÉS DE SUS NOMBRES
}

\author{
FRANKLIN GIOVANNI PÚA MORA \\ Facultad de Filosofía \\ Universidad de San Buenaventura. Bogotá
}

\section{RESUMEN}

Se parte de la consideración de la relación entre el nombre y lo nombrado y cómo la denominación es una buena excusa para la reflexión. Se propone abordar tres denominaciones del continente procurando establecer desde los lugares de enunciación de cada una, referentes de discusión que sirvan para la construcción identitaria que abriga lo latinoamericano. Dichas denominaciones son: Hispanoamérica, Indoamérica y Abya yala.

Palabras clave: Denominación, identidad, referentes, Abya Yala, Kuna, nombres.

\section{ABSTRACT}

It begins with the consideration of the relationship between the name and the name and how the denomination is a good excuse for reflection. It proposes to approach three denominations of the continent trying to establish from the places of enunciation of each one, referents of discussion that serve for the identity construction that shelters the Latin American. These denominations are: Latin America, Indoamerica and Abya yala.

Key words: Denomination, identity, referents, Abya Yala, Kuna, names

\section{Introducción:}

No fue necesario que se diera el llamado giro lingüístico en la filosofía contemporánea para que se comprendiera la fuerza y el poder del lenguaje en el pensamiento humano, aunque claro, ésta apreciación general no le quita ningún mérito al esfuerzo de los autores que hace aproximadamente un siglo empoderaron el protagónico lugar del lenguaje en la discusiones filosóficas de los círculos académicos. Sabemos bien que desde la antigüedad la relación del nombre con lo nombrado ha sido un referente fundamental de especulaciones, referencias y reflexiones que, hoy en día nos siguen acompañando.

La conocida discusión entre Crátilo y Hermógenes sobre la función natural o convencional de los nombres en el precursor diálogo platónico mediado, como siempre por Sócrates, abrió un arcoíris 
fabuloso de discusiones y temáticas que diversas disciplinas de las ciencias sociales y las humanidades han reconocido y desarrollado paulatinamente con el transcurso de los siglos.

¿El nombre expresa realmente con exactitud lo que designa o se trata de una convención funcional? Quizá la mejor expresión de un problema filosófico fundamental la hace Jorge Luis Borges en uno de sus más famosos poemas:

Si, como afirma el griego en el Crátilo El nombre es arquetipo de la cosa Está todo el Nilo en la palabra Nilo Y toda la rosa en la palabra rosa.

Más allá de le referencia al producto bizarro del auscultar mistérico sobre el verdadero nombre de Dios, esto es el Golem, la visión poética borgiana recrea de manera directa el problema de la relación entre el ente y el término que lo designa. Nuestra pretensión en la tarde de hoy no es engrosar una lista mucha más preciada de autores que hacen de este problema un derrotero teórico interesante, la pretensión tiene que ver con un nombre: América y una finalidad: valorar la relación entre lo que se ha llamado América y eso que representa, presentando una propuesta de significación que enlaza al tema de la memoria.

Se parte del principio según el cual el nombre que enuncia y el algo enunciado, se enlazan significativamente generando nuevas realidades de pensamiento que, determinantemente, nos llevan a discusiones interesantes.

Dos nombres han sido fundamentales a la hora de entender la construcción identitaria de este lado del mundo: América y Colombia.

Sobre el primero, es mucha la tinta que se ha gastado alrededor de la experiencia del navegante florentino Amerigo o Américo Vespucio (1451-1512), quien dio su nombre a las Indias Occidentales, al parecer por una apreciación del cosmógrafo alemán Martin Waldseemüller, luego de haber realizado expediciones al Nuevo Mundo acompañando a Colon, mediante las cuales contribuyó a divulgar nuevo conocimiento sobre el tamaño de los territorios recién descubiertos -a los ojos europeos-, en Cartas-relatos que remitió a amigos y corresponsales en distintas partes del viejo continente. Así, Waldseemüller en un mapamundi que acompañaba un folleto titulado Cosmographiae introductio denominó al nuevo continente Americi Terrae, es decir las tierras de Américo. Bartolomé de las Casas enjuició en su obra a Vespucio considerando que se había cometido una injusticia con Colón, pues la denominación correcta para el continente debía ser Colombia.

Estas anotaciones constituyen lugares comunes de lo que hace cualquier explorador en tierras desconocidas, con esto se puede entender la visión colonial hecha crónica. El navegante florentino lo expresaba así: "En aquellos países hemos encontrado tal multitud de gentes, que nadie podría imaginar, como se lee en el apocalipsis" (Forero Benavides, 1992, p. 4).

Las descripciones vespucianas tuvieron amplia acogida en Europa, no solo por la enorme curiosidad sobre las características de los "nuevos" territorios, sino también por las informaciones sobre los habitantes de estos lares, en donde temas como la desnudez de los llamados "naturales" aguzaba la imaginación de los habitantes del viejo continente. No faltaron las acusaciones de fantasías ingeniosamente escritas con el fin de desprestigiar al almirante genovés.

En un reconocido texto de 1958, el pensador mexicano Edmundo O'Gorman plantea una tesis que se constituirá en tema obligado de los estudiosos de lo 
latinoamericano y anticipará discusiones que se avivarán en los ámbitos académicos de finales del siglo XX y comienzos del siglo XXI, se trata de la invención de América, allí argumenta el abogado y filosófico nacido en Coyoacán, que aquella tierra que encontró Colón, no poseía una identidad preestablecida, no se podía predicar de ella que constituyera una entidad definible por los europeos colonizadores, es decir, América no fue descubierta como reza la enunciación usual, América fue inventada.

Ahora bien, América se convierte entonces en el lugar propicio para implantar las ideas, proyectos y utopías que los europeos proyectan, por eso es invención y no descubrimiento, no surge de una vez caracterizado y definible sino que se va haciendo, por eso añade el profesor de la complutense de Madrid: "el nombre de América no es una completa injusticia histórica" (Abellán, 2009, p. 37).

Pablo Guadarrama, en un interesante artículo publicado en la revista Politeia de la Universidad nacional de Colombia contrapuntea frente a la discusión, desde el inicio de su texto enuncia "América no es una invención" (Guadarrama, 1997).

En cuanto al término Colombia, se debe recordar cómo, lo que hoy constituye la actual República de Colombia es, el constructo histórico que queda de lo que fue, no sólo una denominación que pretendía rendir homenaje al llamado "descubridor", sino también el recuerdo de un proyecto hegemónico que recogió lo mejor del proyecto ilustrado a comienzos del siglo XIX.

Los distintos referentes de significado que se han tenido alrededor del nombre de Colombia tendrían necesariamente que ocupar otro lugar y tiempo de discusión, bástenos con apuntar como la lógica de lo que se podría argumentar alrededor del nombre de América, se puede aplicar también al nombre de Colombia. Ambos nombres juegan un papel en la historia simbólica de pueblos que de todas maneras continúan preguntándose por su ser y su quehacer en el siglo XXI.

\section{Hispanoamérica}

El nombre de Hispanoamérica se debe a Francisco de Miranda. El viajero ilustrado a quien se atribuye la original idea de una patria americana expresada en el proyecto grancolombiano. Muestra indudable del espíritu de la razón ilustrada, Miranda pretende construir un proyecto de nación continental y libre de la metrópoli española. Aguzado por los vientos gloriosos de la Revolución Francesa y con un espíritu cosmopolita que lo acompañó toda su vida, el caraqueño pretende contraponer en distintos pasajes de su obra, en un premeditado juego de símbolos, las nuevas denominaciones que habrían de corresponder con su visionaria concepción de la realidad americana.

A cambio de la designación de españoles americanos, propone el de hispanoamericanos, para designar a los sujetos que estarían obligados a cumplir el destino ilustrado de emancipación. Textos conocidos muestran dicha opción desde sus títulos: "a los pueblos del Continente Colombiano (alias HispanoAmérica)".

Dicha novedosa nominación se intercala en el contexto general de su obra con la opción reivindicadora del "descubridor", esto es, el nombre de Colombia como se puede apreciar en muchos de sus apartes y en el bautizo que hace de su periódico (El Colombiano) y la denominación que da a sus archivos (colombeia), pero sobre todo, la afirmación del sentido de la alteridad que implica 
la denominación (Bohórquez, 2006, p. 205).

Interesante anotar como se le podría dar un lugar, en medio de esa representación de alteridad, al término Hispanoamérica. Según la filósofa venezolana Carmen Bohórquez, el apelativo no representaba necesariamente una opción afirmadora de la identidad, más bien se trataría de un intento por mostrar la ilegitimidad del proyecto colonizador de la metrópoli ibérica (Bohórquez, 2006, p. 209).

En contraste, el filósofo cubano Miguel Rojas Gómez, afirma la significación positiva del término, basándose en lo que considera una ruptura de continuidad y continuidad en la apertura, esto es la reivindicación de la cultura propia, en medio de la búsqueda de la libertad. Encontrándose así en un punto que reconoce la unidad en la diversidad (Rojas Gómez, 2011, p. 117).

Argumenta Rojas Gómez que el termino Hispanoamérica "significaría un re-tomar y un reencuentro con lo español en igualdad de libertad, conservándose la comunidad de cultura forjada durante la colonia" (Rojas Gómez, 2011, p. 119). El foco de atención aquí tiene que ver con el hecho de que dicho reencuentro admite la aspiración libertadora, no solo de los criollos hispanoamericanos, sino también, de quienes conformarían ese nuevo pueblo: indios, negros, cruzados o mestizos, en quienes la cultura española se transformaría, en términos libertarios, en el centro de ese nuevo pueblo ahora llamado hispanoamericano.

Sin negar lo interesante de ambas interpretaciones, se puede apreciar en Miranda una característica de lo que Benedict Anderson considera el aspecto central de la configuración de los nacionalismos modernos, esto es, la dinámica de la comunidad imaginada.
El ilustrado caraqueño incluye dentro de su concepción de comunidad nacional, aquellos sectores que completarían y harían realidad, ese proyecto de nación continental y producto de un proceso emancipador. No se pone en duda el protagonismo de los criollos descendientes de los españoles, pero se pretende resemantizar su lugar en la nueva sociedad mediante el papel de guía rector para el proceso independentista de los antes llamados "españoles americanos".

La denominación Hispanoamérica entonces, sigue la lógica emancipadora del pensamiento ilustrado americano. El protagonismo del sector criollo se expresa en la configuración de un nuevo proyecto, incluyente en el horizonte libertario, pero que tendría que pasar por la puesta a prueba de la implementación de nuevas naciones en las que, no siempre por desgracia, la inclusión y la apertura hacia el otro, fueron necesariamente, los rasgos sobresalientes.

\section{Indoamérica}

La aurora del pensamiento filosófico latinoamericano a inicios del siglo XX se presentó como una oportunidad prometedora para retomar algunos de los temas que se habían dejado de lado merced a la supremacía de las temáticas del positivismo decimonónico. Lo que algunos autores reconocen como el entorno arielista (Devés Valdés, 2000) o el antipositivismo (Guadarrama, 1995) o la etapa de las metafísicas y las ontologías (Marquínez et al, 1996) comprende de manera aproximada las tres primeras décadas del siglo XX. La herencia positivista se ve cuestionada y las preguntas por los temas de la identidad y la cultura adquieren un nuevo protagonismo.

El nuevo siglo entonces se presentó como una posibilidad de búsqueda de lo propio para varios de los pensadores 
del subcontinente. No debe extrañar que allí florecieron inquietudes que acompañaron el devenir del pensar latinoamericano a lo largo del siglo XX. El político y pensador peruano Víctor Raúl Haya de la Torre en una conferencia dictada en el Anfiteatro de la Escuela nacional Preparatoria de México en 1927 dijo: "Hispanoamericanismo igual colonia; Latinoamericanismo igual independencia y república; Panamericanismo igual imperialismo e Indoamericanismo igual unificación y libertad" (Haya de la Torre citado por Devés Valdés, 2000, p. 128).

¿Qué entorno de pensamiento se encuentra detrás de dicho rechazo de la denominación hispanoamericana? Para Haya de la Torre es una cuestión de síntesis, pues se trata de la "unidad superior de los que sostienen la tesis del "hispanoamericanismo" y la antítesis del "latinoamericanismo". El concepto de Indoamérica completa la tríade, porque en su valor de síntesis incorpora todas las razones de uno y otro lado" (Haya de la Torre, 1991, p. 105).

Contrasta el carácter sintético que pretende expresar el líder aprista con la equiparación de la denominación hispanoamericana y el entorno colonial. Tal vez una ubicación del contexto de pensamiento del momento pueda ser útil. Los años 20 del siglo pasado ven el surgimiento del indigenismo latinoamericano, momento de reivindicación de lo telúrico como inspiración del deseo de reconocimiento y transformación, empoderamiento de la figura del indígena, fenómeno apreciable en la literatura del momento, además, la búsqueda de lo propio permite la posibilidad de exploraciones semánticas en donde el prefijo indo adquiere relevancia.

Según Devés Valdés (2000) el énfasis social de las búsquedas identitarias del momento llevó a una primera etapa con vocación latinista, que se vería movida a una opción propiamente indigenista para la etapa comprendida entre 1915 y 1930. Las luchas sociales de la época, gloriosamente representadas por la Revolución Mexicana, definitivamente dejaron una influencia clara en las exploraciones intelectuales de los letrados latinoamericanos que, tomando conciencia de aquello que podía ser constituido como eje identitario, voltearon la vista hacia lo originario -como le diríamos hoy- en un intento de diferenciación y en una búsqueda de derroteros tanto teóricos como de guía de proyectos políticos emancipatorios.

En el ámbito del pensamiento colombiano sin duda es el polígrafo de origen caldense Otto Morales Benítez quien ha dado un impulso valioso a la reflexión sobre lo indoamericano a través de su teoría sobre el mestizaje como factor que "condiciona el itinerario histórico y el porvenir del continente" (Morales Benítez, 2000, p. 612). De este modo la consideración del motor histórico del devenir identitario esto es, el mestizo, se plantea como "el gran salto que hace Indoamérica hacia su propia predestinación" (Morales Benítez, 2000, p. 612).

Sin duda, con la denominación indoamericana se hace justicia con la deuda simbólica que se tiene alrededor del pasado ancestral y su papel colonizado y subyugado en el proceso expansionista de Occidente. Sin embargo, conviene ensayar tal vez otras maneras de abordar la interesante temática de la denominación del lugar del mundo que nos corresponde vivir.

\section{Nuestra América}

Si bien la enunciación original la realiza el sacerdote y escritor barroco neogranadino Hernando Domínguez Camargo en el siglo XVII, no cabe la menor duda del protagonismo histórico 
que le imprimió al concepto compuesto en términos de posesión, el prócer, poeta y pensador cubano José Martí. Con el llamado apóstol de la independencia cubana, se encumbra literariamente, se empodera políticamente y se llena de sentido identitario el hecho de reafirmación de lo propio, no sólo en términos de diferenciación de lo que Martí llamaría la "otra" América, sino también en términos de caracterización afirmativa de aquello que debería constituir el espíritu de lo propio en esta parte del mundo.

El eco de la denominación pasaría al siglo XX como inspiración palpable en diversos escenarios políticos, filosóficos y culturales. Cuando en 1968 el maestro peruano Augusto Salazar Bondy se pregunta por la existencia de una filosofía propia surgida de este lugar del planeta, no lo hace por la filosofía latinoamericana, lo hace por la filosofía de nuestra América, generando el que tal vez sea el más conocido debate sobre el tema.

Más recientemente el filósofo argentino mexicano Horacio Cerutti retoma el término en sus textos y lo dimensiona a la par de los grandes temas de su obra: la liberación, la historia de las ideas y la utopía. Además, vale la pena mencionar el proyecto de filosofar nuestro americano de la Universidad Autónoma de la Ciudad de México UACM.

Sin duda, en este término se encuentran estas dos características de la función básica de los nombres: diferenciar y caracterizar. El hecho de una América nuestra implica que al menos existe una que no lo es y con la cual no se podría dar la segunda cuestión, esto es, la caracterización, cuestión no acabada por supuesto, como lo anotaba Abellán, pero proyecto posible, pues es muy razonable que, como lo plantea el filósofo chileno Miguel Rojas Mix, puede ser que "las raíces de la identidad están en el futuro".

\section{Abya Yala}

Los Kuna o Tule son una comunidad originaria cuyo territorio ancestral comprende la esquina norte de Suramérica y el Istmo de Panamá, pueblo milenario que ha gestado un pensamiento complejo en donde los referentes de conocimiento se articulan de manera interesante con formas de pensamiento complejo, que se representan por ejemplo en las conocidas molas que ya se han incorporado a los circuitos de distribución de productos artesanales en muchos lugares.

Para los Kuna, como para tantas otras culturas de la América originaria, el mundo ha sido creado y destruido tres veces, en el mundo actual se recoge entonces el aprendizaje de estos intentos anteriores en un sentido de proceso de "madurez", por eso son capaces de distinguir entre Kuna Yala, el lugar que se habita u Abya Yala, la tierra en plena madurez que se establece como la creación completada. Algunas acepciones hablan de "territorio de sangre" esto es, territorio de la madre.

El término ganó notoriedad cuando en una de las conferencias de los pueblos indígenas de América a finales de los años setenta del siglo pasado, el líder aymara Takir Mamani advirtió que la utilización en los documentos oficiales del movimiento indígena del nombre de América, equivalía a someter la identidad indígena a los invasores y sus herederos.

Enrique Dussel en su obra de referencia sobre el Quinto centenario (Dussel, 1994, p. 93) cuenta como el poeta y educador Kuna Aiban Wagua en su obra: “iMedio Milenio!" Algunas consecuencias actuales de la invasión europea a Abia Yala. Visión indígena", escribe: "Los kunas desde antes de la llegada de los europeos, conocían a esta tierra como Abia Yala, que significa: tierra madura, 
tierra madre grande, tierra de sangre. $Y$ hoy se nos impuso el nombre del italiano: América".

Vale la pena anotar que en las cumbres continentales de los pueblos indígenas, la denominación Abya Yala, cobra pleno sentido, así ocurrió desde la III Cumbre realizada en 2007 en Guatemala. Causa curiosidad que no fue ningún representante del pueblo Tule quien hizo la propuesta, que de todas maneras ya se ha generalizado para la generalidad de los pueblos originarios del continente.

La denominación además le hace justicia a una cuestión debatida en algunos círculos académicos que pueden darnos señas de las discusiones que se generan alrededor de algunos de nuestros esquemas coloniales, se trata de la afirmación según la cual los antiguos habitantes de Abya Yala no tenían conciencia de la extensión territorial correspondiente al continente entero. Es claro que las alusiones de estas comunidades al lugar de origen dentro de sus sistemas de representación territorial son mayoría, pero es difícil de refutar lo que la arqueología y la lingüística tiene que decir. Piezas de oro suramericanas halladas en los cenotes mayas, noticias recogidas en la colonia sobre los productos de intercambio en distintos lugares del continente, cuando no, las palabras, dentro de ellas Abya Yala como ese territorio extendido y cuya inmensidad no se ignora en el pensar mítico de los pueblos originarios.

\section{Posibilidad:}

Lugar de enunciación privilegiado, el movimiento indígena es consciente, y no sólo por razones del accionar político, de la fuerza de una denominación, fuerza que no desconoce la enorme diversidad presente en general en las culturas de la antigua Abya Yala. De este modo, más que un concepto homogeneizador, la denominación se presenta en términos de una doble oportunidad que queremos resaltar. La primera oportunidad tiene que ver con el tema de la identidad y la segunda con el tema de la memoria, veamos.

La identidad cultural no remite a un preexistencia esencialista de factores que deben ser desentrañados de manera sistemática, tal y como lo presentan los discursos mediáticos cargados de una y otra ideología, según el caso. Aclaremos, no molesta la toma de posición alrededor de la concepción identitaria, lo que no parece tener un tono de sinceridad adecuado es la pretensión del desentrañar, del encontrar el mito fundacional perdido bajo unos parámetros preestablecidos.

Sírvanos sinópticamente el ejemplo de la propuesta identitaria del proyecto político del uribismo que durante ocho años se presentó como referente hegemónico en la Colombia de la primera década del siglo XXI. Unos íconos determinados se empoderaron como referentes de la identidad reencontrada a través de un proyecto político que por supuesto privilegia ciertos valores por encima de otros. Esperamos ocuparnos del tema en otro espacio más apropiado, lo que queremos resaltar en este momento es que este tipo de construcción identitaria marcada por la verticalidad no parece encontrar eco en las necesarias reflexiones sobre el tema que nos propusimos trabajar en esta jornada. La identidad cultural precisa del otro para ser construida, para ser enunciada y para ser dinamizada, pues bien, el primer referente de oportunidad del término Abya Yala tiene que ver justamente con la afirmación identitaria frente a otro, otro frente al que se enuncia el orgullo de una historia de discriminación y ocultamiento, de negación y asimilación, otro que de todas maneras tiene un papel en la construcción de las identidades 
indígenas contemporáneas más allá de esencialismos románticos o abstractos.

La segunda oportunidad tiene que ver con una pregunta que hemos realizado varias veces en el salón de clase y en otros escenarios de discusión, esto es, el papel de la filosofía en la generación de los necesarios debates de la realidad que configura el contexto del cual se desprenden las ideas que los académicos debaten.

En otro lugar hemos expresado la opinión de que la filosofía tiene, entre otras, una labor que algunos profesionales dedicados a la disciplina tristemente ignoran con cierta frecuencia, esto es la preservación del saber a través de la palabra que recuerda, guardando las distancias es lo que realiza un sabedor o sabedora dentro de una comunidad originaria, atesorar las palabras que sirven de base al recuerdo, claro, en el pensamiento occidental esto se adereza con las necesarias exigencias de la interpretación y la crítica, en síntesis, la filosofía tiene un papel fundamental que jugar en la conservación de la memoria (Osorio, 2007, p. 197). Pues bien, Abya Yala como propuesta de enunciación se constituye como una opción no sólo de reivindicación del movimiento indígena, se presenta también como opción identitaria y como posibilidad de conservación de la memoria, memoria que no sólo le pertenece a los pueblos indígenas, memoria que constituye una base de discusión y referencia de lo que se pretende en la actualidad como construcción de proyectos conjuntos que reivindiquen la posibilidad de una alternativa frente a la herencia colonial que nos ha constituido.

No se trata de negar el aporte del ancestro originario africano, como bien podría refutarse, es más, la posibilidad de construcción de un término reivindicativo de la memoria en un sentido aún más integral precisa de una discu- sión sobre los términos que actualizan la presencia afro, asunto que se deja traslucir en algunos debates del movimiento negro o afro, la sola cuestión de la implicación de cada una de esas denominaciones así lo demuestra, algo así como una Abya Yala-afro-latina no parece una denominación inadecuada aunque la enunciación efectivamente parezca barroca, cuestión nada lejana de nuestros mezclados imaginarios. Este sería un aspecto para futuras discusiones interesantes.

En síntesis, la denominación evita las insatisfacciones generadas por otros términos al caer bajo la sospecha de perpetuar la realidad colonial, rescata la preocupación por lo ancestral de Indoamérica y retoma el espíritu nuestro americano sin duda, por eso a manera de insinuación esta denominación para hacer un poco de memoria.

Imposible terminar sin remitir al valor fundamental de la palabra desde un lugar de enunciación cargado de autenticidad. El poeta y educador Tule Aiban Wagua nos dice:

Deja, hermano indio, que tus hijos

Se agarren a los abuelos

Que, aun después de muertos, Saben resistir y no se bambolean. Hermano amigo, Haz de tu palabra capaz de curar heridas, Arma y barricada.

Prohíbete una lágrima de debilidad, Regala a tu pueblo hijos libres, Renueva tu orgullo indio.

No importa lo que digan:

iSomos propietarios de abia yala!

(wagua, prometeo Revista latinoamericana de poesía Número 86-87. Julio de 2010.)

Curioso que el poema en mención se titule: cada cosa con su nombre. 


\section{BIBLIOGRAFÍA}

Abellán, José Luis (2009) La idea de América: origen y evolución. Madrid: Iberoamericana; Frankfurt am Main: Vervuert.

Bohórquez, Carmen (2006) Francisco de Miranda. Precursor de las independencias de la América Latina. Caracas: El perro y la rana Ediciones.

Devés Valdés, Eduardo (2000) El pensamiento latinoamericano en el siglo XX: entre la modernización y la identidad: tomo I del Ariel de Rodó a la CEPAL (1900-1950).

Forero Benavides, Abelardo. El nombre de América. En: Revista Credencial Historia (Bogotá). -- No. 26 (Feb. 1992) - p. 4-7.

Guadarrama González, Pablo. "La Huella de España en América y de América en España”, Politeia. Revista de la Facultad de Derecho, Ciencias Políticas y Sociales. Bogotá. 1997. Nro. 20. págs. 135-148.

Guadarrama González, Pablo (1995) Antipositivismo en América Latina. Bogotá: UNAD.

Haya de la Torre, Víctor Raúl (1990). Indoamérica. En:Temas de filosofía de la cultura latinoamericana. Bogotá: Editorial El búho.

Marquínez, Germán et al. (1996) La filosofía en América Latina. Santafé de Bogotá: Editorial El Búho.

Morales Benítez, Otto (2000) Obras. Tomo III. Creación y crítica literaria en Colombia. Santafé de Bogotá: Instituto Caro y Cuervo.

O ‘Gorman, Edmundo (1992) La invención de América. México: Secretaría de Educación Pública.

Osorio Garcés, Betty (2007) Construcción de la memoria indígena. Bogotá: Siglo del Hombre-Universidad de los Andes.

Platón (1983) Crátilo. Bogotá: Universidad Nacional de Colombia.

Prometeo. Revista Latinoamericana de Poesía Número 86-87. Julio de 2010

Rojas Gómez, Miguel (2011) Identidad cultural e integración. Desde la llustración hasta el Romanticismo latinoamericanos. Bogotá: Editorial Bonaventuriana.

Rojas Mix, Miguel (1991) Los cien nombres de América. Barcelona: Editorial Lumen. 